\title{
Variations of atmospheric methane supply from the Sea of Okhotsk induced by the seasonal ice cover
}

\author{
S. Lammers and E. Suess \\ GEOMAR, Forschungszentrum für marine Geowissenschaften, Kiel, Germany \\ M. N. Mansurov \\ Sakhalin Institute for Oil and Gas Research, Okha, Sakhalin, Russian Federation \\ V. V. Anikiev \\ Russian Academy of Science, Institute of Oceanology, Moskow, Russian Federation
}

\begin{abstract}
Measurements of dissolved methane in the surface waters of the western Sea of Okhotsk are evaluated in terms of methane exchange rates and are used to assess the magnitude of seasonal variations of methane fluxes from the ocean to the atmosphere in this area. Methane concentrations northeast of Sakhalin were observed to range from $385 \mathrm{nmol} \mathrm{L}-1$ under the ice cover in winter to $6 \mathrm{nmol} \mathrm{L}-1$ in the icefree midsummer season. The magnitude of supersaturations indicates that this part of the Okhotsk Sea is a significant source for atmospheric methane. From the seasonal variation of the supersaturations in the surface waters it is evident that the air-sea exchange is interrupted during the winter and methane from sedimentary sources accumulates under the ice cover. According to our measurements an initial early summer methane pulse into the atmosphere of the order of $560 \mathrm{~mol} \mathrm{~km}^{-2} \mathrm{~d}^{-1}$ can be expected when the supersaturated surface waters are exposed by the retreating ice. The methane flux in July is approximately $150 \mathrm{~mol} \mathrm{~km}^{-2} \mathrm{~d}^{-1}$ which is of the order of the average annual flux in the survey area. The magnitude of the seasonal $\mathrm{CH}_{4}$ flux variation northeast of Sakhalin corresponds to an amount of $7.3 \times 10^{5} \mathrm{~g} \mathrm{~km}^{-2}$ whereby $74 \%$ or $5.4 \times 10^{5} \mathrm{~g} \mathrm{~km}^{-2}$ are supplied to the atmosphere between April and July. For the whole Sea of Okhotsk the annual methane flux is roughly $0.13 \times 10^{12} \mathrm{~g}$ (terragrams), based on the assumption that $15 \%$ of the entire area emit methane. Variations of long-term data of atmospheric methane which are recorded at the same latitude adjacent to areas with seasonal ice cover show a regional methane pulse between April and July. The large-scale level of atmospheric methane in the northern hemisphere undergoes an amplitudinal variation of about 25 parts per billion by volume (ppbv) which translates into approximately $36 \mathrm{Tg}$. Thus the estimated $0.6 \mathrm{Tg}$ of ice-induced methane dynamics in northern latitudes can hardly explain this seasonal signal. However, the effects of seasonal ice cover on pulsed release of methane appear strong enough to contribute, in concert with other seasonal sources, to characteristic short-term wobbles in the atmospheric methane budget which are observed between $50^{\circ} \mathrm{N}$ and $60^{\circ} \mathrm{N}$.
\end{abstract}

\section{Introduction}

Since the atmospheric methane level was recognized to increase at an average rate of $1 \% \mathrm{yr}^{-1}$ [Rasmussen and Khalil, 1981; Blake and Rowland, 1988], intensive research led to the conclusion that the various terrestrial

Copyright 1995 by the American Geophysical Union.

Paper number 95GB01144.

0886-6236/95/95GB-01144\$10.00 sources account for about $98 \%$ of the global atmospheric methane production of $540 \mathrm{Tg} \mathrm{yr}^{-1}\left(1 \mathrm{Tg}=10^{12} \mathrm{~g}\right)$ [Cicerone and Oremland, 1988]. The contribution from oceans and continental shelves is still uncertain but is thought to be insignificant because estimates range from $0.005 \%$ to about $3 \%$ of the global production [ Conrad and Seiler, 1988; Cicerone and Oremland, 1988; Bange et al., 1994]. A recent reassessment based on a compilation of published data indicates that the global marine methane emission ranges between $11 \mathrm{Tg}$ and 
$18 \mathrm{Tg}$, whereas $75 \%$ of this flux are attributed to shelf regions [Bange et al., 1994]. A growing number of investigations in both oceanic and shelf environments indicate a nonhomogenous distribution of marine methane sources [Owens et al., 1991; Lammers et al., 1995; Kvenvolden et al., 1993]. The presently available data grid is not large and dense enough to cover all potential marine contributions and to approximate the mass balance of the methane linked to the marine carbon cycle. Recently, it was reported that the generally increasing trend of atmospheric methane is superimposed by a seasonal variation, predominantly in the northern hemisphere with maxima during the fall, winter, and spring months and relatively short minima during the summer. [Steele et al., 1992; Lang et al., 1990]. The frequency of these variations and the distribution of the minima and maxima is suggested to reflect a seasonality of the main sink of atmospheric methane, that is, the oxidation of $\mathrm{CH}_{4}$ by $\mathrm{OH}$ radicals in the stratosphere. But compared to the southern hemisphere the more complex seasonal cycle in the northern hemisphere results from a stronger interference between sources and sinks [Fung et al., 1991; Steele et al., 1992]. However, also the marine environment is considered as a possible contributor to the seasonal variations as well as to the long-term increase, particularly in northern shelf areas where important methane sources in the form of gas hydrates and hydrocarbon deposits exist and the gas fluxes through the sea surface might be frequently increased by weather-induced convection or inhibited by ice cover [Lammers et al., 1995; Kvenvolden et al., 1993].

The Sea of Okhotsk is one of the marginal seas with the highest potentials for a large marine contribution to the atmospheric methane in the northern hemisphere. Sources, transport, and biochemical turnover of methane are largely controlled by the supply from sedimentary sources which have been the subject of extensive previous investigations [Cranston et al., 1994; Ginsburg et al., 1993; Obzhirov et al., 1989; Obzhirov, 1992; Zonenshayn et al., 1987; Geodekyan et al., 1976].

In an initial large-scale survey Geodekyan et al. [1976] identified two areas where anomalously high concentrations of methane and the presence of $\mathrm{C}_{2+}$ - hydrocarbons in the near-surface sediments indicated major sources of thermogenic gas emissions. These areas are the structural Tinrio Basins in the northeastern Sea of Okhotsk, and the entire shelf and slope off eastern Sakhalin. Later Avdeiko et al. [1988] and Zonenshayn et al. [1987] discovered hydrothermally generated hydrocarbons and large-scale methane plumes in the water column of the eastern part of the Sea of Okhotsk bordering the Kuril Island chain. Obzhirov $[1989,1992]$ in many exploration-oriented surveys ascertained the detailed picture and the magnitude of $\mathrm{CH}_{4}$ anomalies in the bottom water of these areas. Conservative extrap- olations suggests that more than $20 \%$ of the area of the Sea of Okhotsk might be underlain by $\mathrm{CH}_{4}$ accumulations both of biogenic and thermogenic origin. Currently, large oil and gas fields are producing along the $\mathrm{NE}$ coast of Sakhalin, and significant methane plumes were found up and down the coast which contribute significantly to the atmospheric methane in this region.

Water depth and low bottom water temperatures in most parts of the Okhotsk Sea provide conditions which favour the formation of gas hydrates. In fact, gas hydrate samples were found to be associated with the reported sedimentary methane sources of the NE coast of Sakhalin as well as inferred from pore water analyses around the gas fields there [Cranston et al., 1994]. The well-known bottom-simulating-reflector, indicative of gas hydrates, was also detected by seismic profiling near Paramushir Island [Zonenshayn et al., 1987].

Under the influence of the Siberian continental climate the entire Sea of Okhotsk is covered by sea ice reaching several meters in thickness during the winter season from about October to April. The seasonal appearance and disappearance of the ice cover may there-

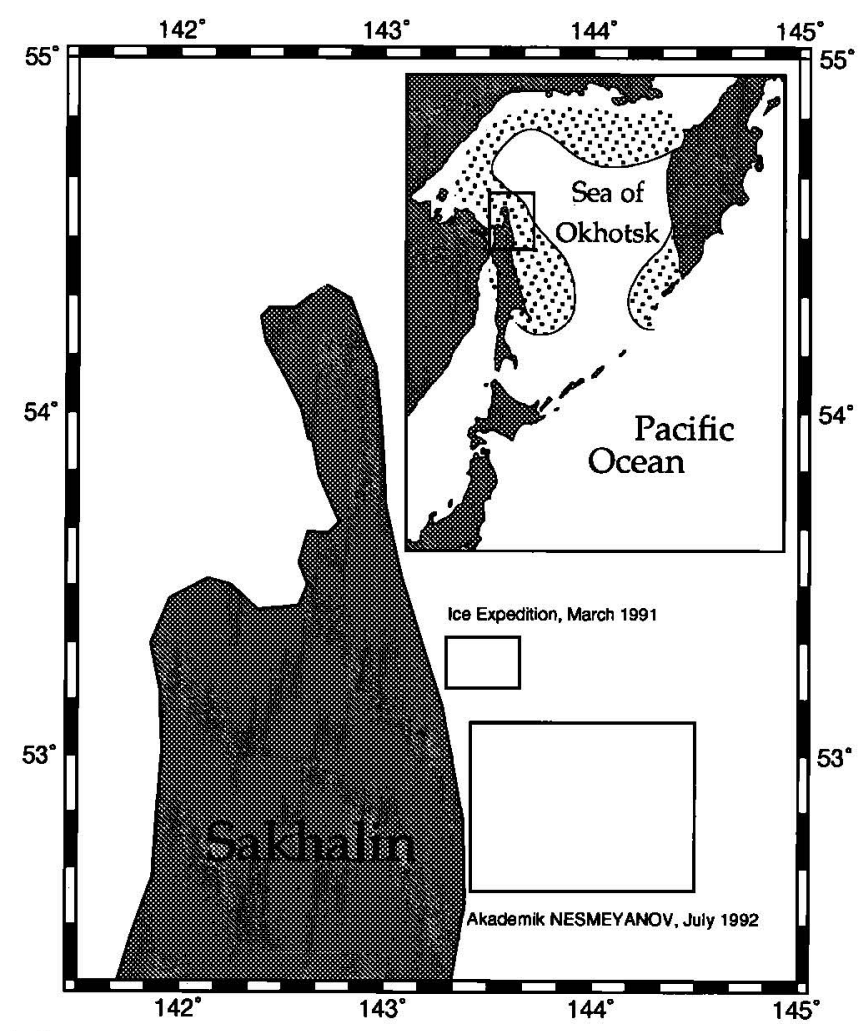

Figure 1. Locations of the areas at the NE coast of Sakhalin which were surveyed during an ice expedition in March of 1991 and a research cruise with $R V$ Alexandr Nesmeyanow in July of 1992 (cf. Figure 2). The inset map shows the approximate limits of anomalously high $\mathrm{CH}_{4}$ in surface sediment, according to Geodekyan et al. [1976], Avdeiko et al. [1988], Zonenshayn et al. [1987], Obshirov [1992], and Obzhirov et al. [1989]. 
fore exert a modulation onto the release of methane from this marine environment, as was also hypothesized for the Beaufort Sea by Kvenvolden et al. [1993] . As a consequence of both high marine methane stock from the sedimentary sources and seasonal variations in airsea exchange parameters, this region offers unique conditions to consider the role of seasonal sea ice on the marine methane cycle in high latitudes. Samples from two expeditions to the Sea of Okhotsk, one in the winter of 1991 and the other in the summer of 1992, provide the data necessary to attempt a preliminary estimation of the methane fluxes and the modulation by sea ice in this region.

It is important to note that although the two sets of samples were not taken at exactly the same positions (Figure 1), a sufficiently large data set from all along the northeastern parts off Sakhalin indicates that over a distance of more than $300 \mathrm{~km}$ between $51^{\circ} \mathrm{N}$ and $54^{\circ} \mathrm{N}$, the distribution of dissolved methane in the water column over the shelf and slope is almost identical [Obzhirov, 1992]. The distance between the summer and winter sampling sites of this study is less than $40 \mathrm{~km}$ at the most and both are part of the same active vent region. An assessment of the interannual variability of methane concentrations in this area and its control by hydrographic conditions is currently in progress. Methane concentrations in ice-covered surface waters off Sakhalin are compared with values observed under midsummer conditions. The magnitude of supersaturation and the seasonal difference in the methane contents are evaluated in order to assess the rates and dynamics of methane fluxes from this shelf area to the atmosphere. On the basis of these evaluations the ice-induced variations of atmospheric methane fluxes in the northern hemisphere are estimated.

\section{Methods}

Methane measurements were made on two expeditions in the winter 1991 and in the summer 1992 northeast of Sakhalin between $52^{\circ} 30^{\prime} \mathrm{N}$ and $53^{\circ} 30^{\prime} \mathrm{N}$ (Figure 1) in order to attempt a preliminary estimation of the methane fluxes and the modulation of sea ice in the Sea of Okhotsk. The winter survey by helicopter was performed in cooperation with the Sakhalin Institute for Oil and Gas Research in Okha in March 1991. At six locations seawater samples were recovered from $5 \mathrm{~m}$ below the surface through holes drilled in the ice sheet. The water was collected in gas tight Alltech 5layer gas sampling bags using a 1.2 liter stainless steel sampler and was immediately preserved by $\mathrm{HgCl}_{2}$. Because of the low air temperatures of $-15^{\circ} \mathrm{C}$, the flexible gas sampling bags of extremely low diffusion for $\mathrm{CH}_{4}$ were used for the transportation of the deep frozen samples to the GEOMAR laboratory at Kiel. The sum- mer values were obtained in July 1992 during a cruise with RV Akademik Alexandr Nesmeyanov, where surface water samples were taken at 12 stations and immediately analysed on board for dissolved methane. The dissolved gases were extracted from the water using a combined vacuum and ultrasonic method [Schmitt et al., 1991; Lammers and Suess, 1994] and were analysed for methane by gas chromatography.

\section{Results}

The $\mathrm{CH}_{4}$ concentrations obtained from the surface waters during both expeditions are shown in Figure 2. The winter situation is characterized by an extremely high methane anomaly that increases in a NE direction from $95 \mathrm{nmol} \mathrm{L}^{-1}$ to $385 \mathrm{nmol} \mathrm{L}^{-1}$. For comparison, the background value of dissolved methane in oceanic deep water is between 0.7 and $2 \mathrm{nmol} \mathrm{L}^{-1}$ and in surface waters equilibrated with an atmospheric methane concentration of 2.0 parts per million by volume (ppmv) (which is in the upper range of presently

a)

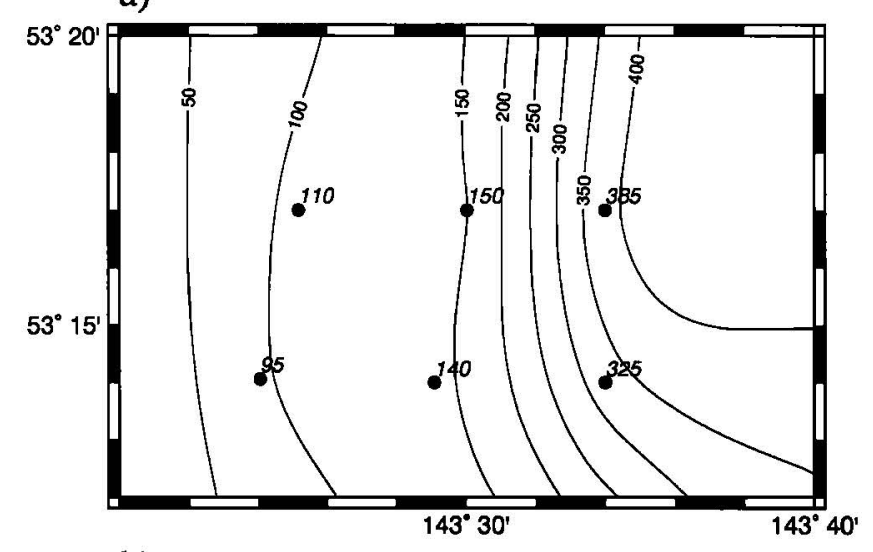

b)

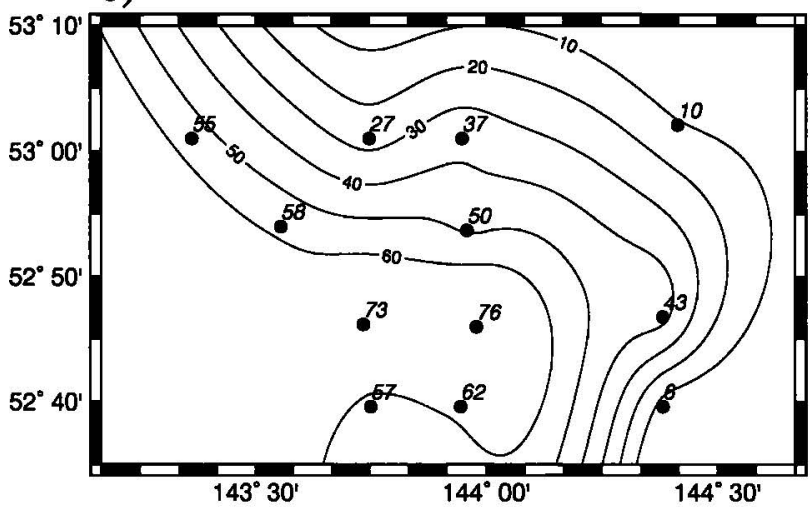

Figure 2. (a) Dissolved $\mathrm{CH}_{4}$ in the surface waters NE of Sakhalin, in March of 1991 below the ice cover and (b) in July of 1992. The concentrations measured at the sample locations and the values of the contour lines are given in nanomoles methane per liter seawater. Note that the areas are different in size (cf. Figure 1). 
observed values) the concentration of $\mathrm{CH}_{4}$ would be about $4 \mathrm{nmol} \mathrm{L^{-1 }}$ at $0^{\circ} \mathrm{C}$ and $34 \times 10^{-3}$ salinity [ Wiesenburg and Guinasso, 1979]. Accordingly, the March values represent a supersaturation of 2000 - $9500 \%$ relative to atmospheric conditions. The summer values range between 6 and $76 \mathrm{nmol} \mathrm{L^{-1 }}$ and are considerably lower than those observed under the ice. The lowest values are just about twice the level of equilibrium with the atmosphere $\left(3 \mathrm{nmol} \mathrm{\textrm {L } ^ { - 1 }}\right.$ at $10^{\circ} \mathrm{C}$ and $34 \times 10^{-3}$ salinity) and the maximum is even lower than the lowest concentration measured during the winter. Nevertheless, the average summer values represent a supersaturation of $1000 \%$ relative to the atmospheric $\mathrm{CH}_{4}$ content.

\section{Discussion}

The interpretation of these data in terms of methane exchange is considered under constant atmospheric parameters, that is, the partial pressure of atmospheric methane at 2.0 ppmv and a wind velocity at the boundary layer of $7 \mathrm{~m} \mathrm{~s}^{-1}$. Under circumstances where surface waters were only slightly supersaturated, changes in atmospheric methane and wind velocities were shown to account for considerable short-term variations in exchange and even inversions of methane exchange such that the ocean surface could act as a methane sink [Lammers and Suess, 1994]. However, with respect to the magnitude of supersaturations off Sakhalin, such atmospheric variations are insignificant for the long-term estimation of methane fluxes in this region.

The methane flux through the air-sea interface is a function of the concentration gradient $\Delta C$ between both phases and the exchange coefficient or "piston velocity" $k$, as described by Wanninkhof [1992]:

$$
F=0.31 v^{2}\left(\frac{S c}{660}\right)^{-\frac{1}{2}} \Delta C
$$

The concentration gradient $\Delta C$ refers to the difference between the methane concentration in the water and the equilibrium concentration calculated according to Wiesenburg and Guinasso [1979]. The Schmidt number $S c$ is defined as the ratio between the kinematic viscosity of the water and the diffusion coefficient of the gas in question. In the case of methane in seawater $S c$ can be calculated from a cubic function of the temperature after Wanninkhof [1992]:

$$
S c=2039.2-120.31 t+3.4209 t^{2}-0.040437 t^{3}
$$

Since the gas exchange through the boundary layer varies with the square of the wind velocity, it is evident that sea ice can act as a very effective barrier just by reducing the wind velocity at the interface to zero, even if the sea ice is partly permeable to gas. Under such conditions, it is reasonable to expect only diffusive gas exchange through the ice cover and the onset of a maximum of methane flux into the atmosphere when the ice retreats.

On the basis of (1) and (2) the methane fluxes are calculated for water temperatures of $0^{\circ} \mathrm{C}$ for spring and $10^{\circ} \mathrm{C}$ for summer, whereby the supersaturations at the time of ice melting are assumed equal to those measured in March of 1991. If a concentration gradient $(\Delta C)$ of $270 \mathrm{nmol} \mathrm{L^{-1 }}$ is taken, an initial methane pulse of $560 \mathrm{~mol} \mathrm{~km}^{-2} \mathrm{~d}^{-1}$ (or $8.9 \mathrm{mg} \mathrm{m}^{-2} \mathrm{~d}^{-1}$ ) can be expected when ice melting in April exposes the supersaturated surface waters to the atmosphere. A $\Delta C$ value of $55 \mathrm{nmol} \mathrm{\textrm {L } ^ { - 1 }}$ in July still corresponds to a methane flux of $150 \mathrm{~mol} \mathrm{~km}^{-2} \mathrm{~d}^{-1}$ (or $2.4 \mathrm{mg} \mathrm{m}^{-2} \mathrm{~d}^{-1}$ ).

In Figure 3 these values for April and July are used to schematically construct the annual flux characteristic for the survey area. Hereby the degassing is assumed to decrease exponentially after the initial peak and to approach a minimum flux between October and March. The total annual methane flux defined by this curve is approximately $7.3 \times 10^{5} \mathrm{~g} \mathrm{~km}^{-2}$ whereby $74 \%$ or $5.4 \times 10^{5} \mathrm{~g} \mathrm{~km}^{-2}$ are supplied to the atmosphere in a relatively short pulse between April and July. In this model, the minimum flux is assessed at $20 \mathrm{~mol} \mathrm{~km} \mathrm{~d}^{-1}$ or $3.8 \times 10^{4} \mathrm{~g} \mathrm{~km}^{-2} \mathrm{yr}^{-1}$ between April and July. Ac-

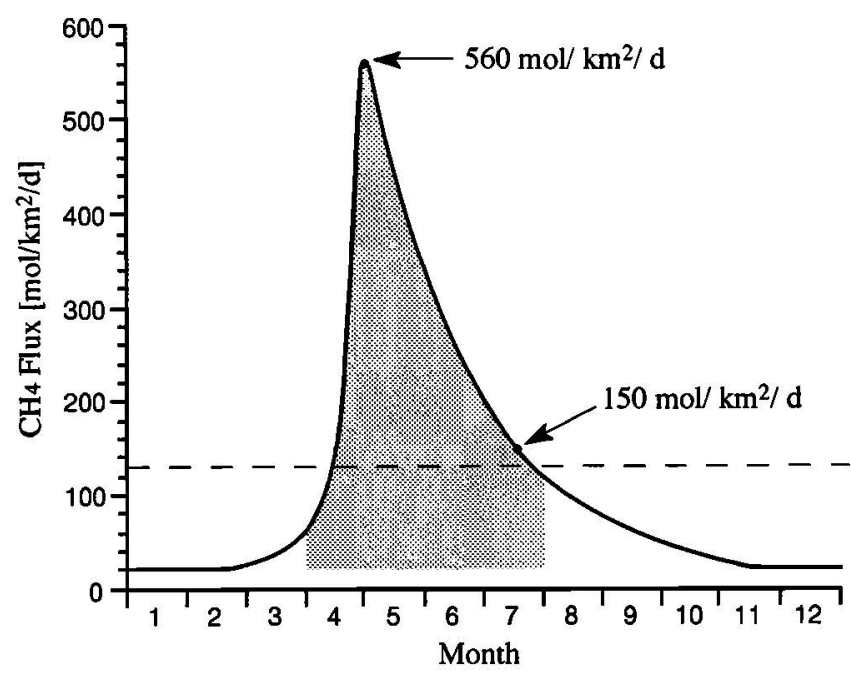

Figure 3. Extrapolated production (flux characteristic) of atmospheric methane in the surveyed area off Sakhalin. The fluxes (moles per square kilometer per day) are calculated from 1 and 2 according to mean $\Delta C$ values of $270 \mathrm{nmol} \mathrm{L}^{-1}$ at $0^{\circ} \mathrm{C}$ in April and $55 \mathrm{nmol} \mathrm{\textrm {L } ^ { - 1 }}$ at $10^{\circ} \mathrm{C}$ in July and an average wind velocity of $\mathrm{v}=7 \mathrm{~m} \mathrm{~s}^{-1}$ throughout the year. The degassing decreases exponentially after the initial flux peak in April and is reduced by the ice cover between October and March. The shaded area represents $74 \%$ of the total annual methane flux which is released between April and July on account of the retreating ice cover. The July value corresponds to the estimated total methane production (dashed line) in this area of the Okhotsk Sea. 
cordingly, the growth and decay of the ice cover approximately accounts for a variation of the atmospheric methane of the order of $6.1 \times 10^{5} \mathrm{~g} \mathrm{~km}^{-2}$ over the whole year and $5.7 \times 10^{5} \mathrm{~g} \mathrm{~km}^{-2}$ between April and July.

The extrapolation of the dynamic methane exchange behaviour to the whole Sea of Okhotsk includes the as yet uncharted assumption that the size and the duration of the observed methane anomaly extends over about $15 \%$ of that part of the ocean. From our knowledge about methane distribution in the Sea of Okhotsk, this is a reasonable estimate [Geodekyan et al., 1976]. Accordingly, the ice induced pulsing of the methane flux from the Sea of Okhotsk ( $15 \%$ of the total area of $1.4 \times 10^{6} \mathrm{~km}^{2}$ ) is calculated to be $0.13 \mathrm{Tg}$ per year or $0.12 \mathrm{Tg}$ between April and July, respectively. Due to the overall uncertainties of the calculation, the iceinduced seasonal variation of the methane flux from the surface of the Okhotsk Sea is estimated as $0.05-0.13 \mathrm{Tg}$ per year.

In this context it is worth noting that Whalen and Reeburgh [1992] showed wetlands releasing methane also on a seasonal cycle. Between freezing and thawing of the Alaskan tundra almost 4 orders of magnitude variations in methane flux were reported $\left(5 \times 10^{-2}\right.$ to $\left.5 \times 10^{2} \mathrm{mg} \mathrm{m}^{-2} \mathrm{~d}^{-1}\right)$. The third quarter of each year between 1987 and 1990, that is, from July to September, consistently showed the highest flux rates. The maximum flux calculated here for the Sea of Okhotsk is $7.6 \mathrm{mg} \mathrm{m}^{-2} \mathrm{~d}^{-1}$ and thus is higher than those reported from the wetlands in the same time of year. However, it is considerably smaller than the methane flux from the wetlands during the fall. Nevertheless, the Alaskan wetlands and the Sea of Okhotsk both generate tightly pulsed methane signals in the northern hemisphere; an important point which will be discussed again later on.

Regarding the interpretation of long-term records of atmospheric methane in the northern hemisphere, this assessment is also instructive to help establish an upper limit for methane fluctuations which are probably induced by the seasonal cycle of the sea ice extent over the entire Arctic. Such a mechanism would complement or modulate the seasonal flux from wetlands. Between February and August the area covered by Arctic sea ice reduces from about $14 \times 10^{6} \mathrm{~km}^{2}$ to $7 \times 10^{6} \mathrm{~km}^{2}$ [Untersteiner, 1990]. Extrapolated from the $0.13 \mathrm{Tg}$ of methane flux from the Sea of Okhotsk, the upper limit for annual ice-induced methane release between $50^{\circ} \mathrm{N}$ and $80^{\circ} \mathrm{N}$ would be $0.6 \mathrm{Tg}$. This is in accordance with suggestions based on measurements in the Beaufort Sea by Kvenvolden et al. [1993], who extrapolated an annual methane release of $0.1 \mathrm{Tg}$ from the seasonally ice-covered Arctic Ocean shelf.

The possible effect of such an ice-triggered methane pulse can only be assessed in relation to the overall annual variability of atmospheric methane. Since 1983 , at-
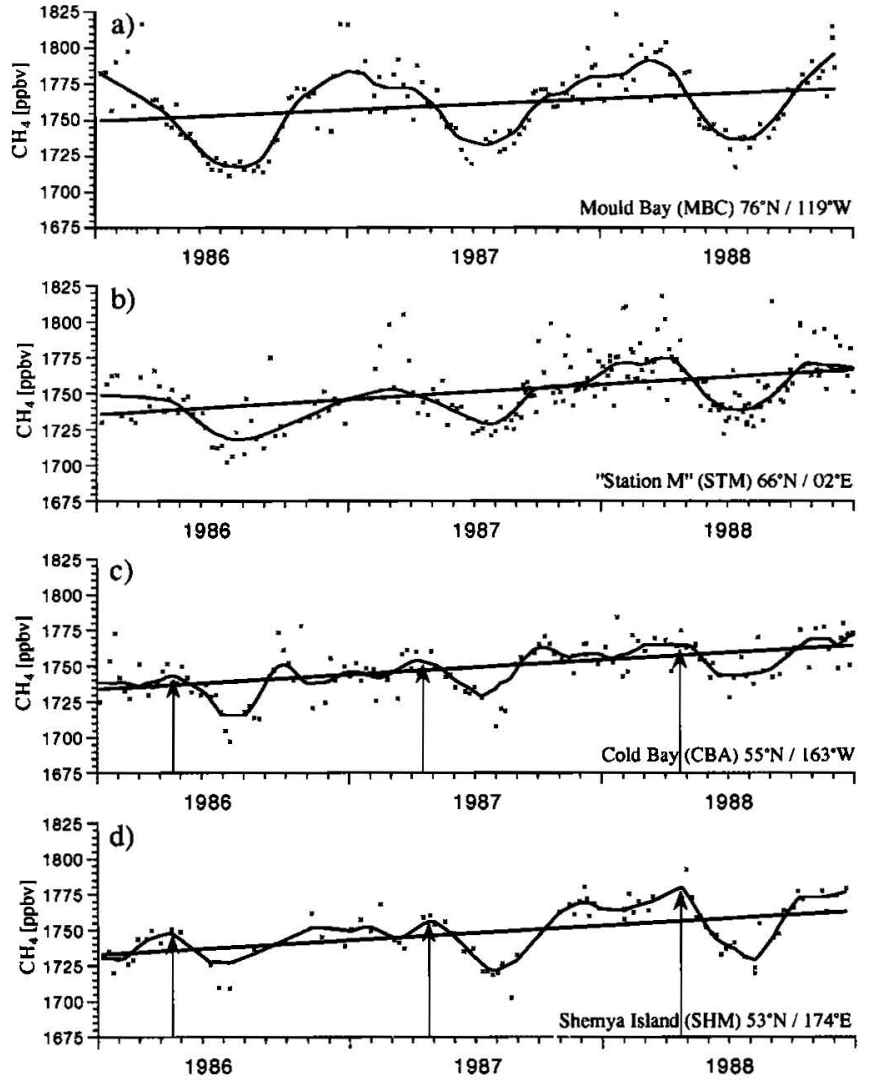

Figure 4. (a) Atmospheric methane records from 1986 to 1988 in northern Canada, (b) in the open North Atlantic, and (c,d) at two locations in the North Pacific between $50^{\circ} \mathrm{N}$ and $60^{\circ} \mathrm{N}$ (cf. Figure 5). The recordings are selected from the NOAA-CMDL "cooperative flask sampling network" [Lang et al., 1990]. Additional to the actual measurements (dots) the smoothed annual cycles (solid curves) and the log-term gradients (solid lines) are plotted. The frequency of the seasonal cycles appears more regular at Mould Bay and "station M", while the amplitude is higher at $76^{\circ} \mathrm{N}$ than at $66^{\circ} \mathrm{N}$. The records from Cold Bay (Alaska) and Shemya Island appear to be more superimposed by cycles of higher frequencies predominantly during the winter period. A short-term increase is observed regularly between March and May and correlates with the suggested ice-triggered methane pulse from adjacent areas.

mospheric methane mixing ratios have been monitored by the U.S. National Oceanic and Atmospheric Administration (NOAA) [Lang et al., 1990]. These measurements are widely recognized and applied in recent models of the annual and long-term variabilities of atmospheric methane [Fung et al., 1991; Steele et al., 1992]. The most remarkable observation from this data set in terms of seasonal variations is an increase of the seasonal amplitude towards the northern latitudes, roughly from $20 \mathrm{ppb}$ at the equator to almost $50 \mathrm{ppb}$ in the Arctic. The mean value of the amplitudinal change for the northern hemisphere is about $25 \mathrm{ppb}$ which roughly 
corresponds to an amount of methane of $36 \times 10^{12} \mathrm{~g}$. This assumes that these variations are only affecting the inventory of $2.4 \times 10^{15} \mathrm{~g}$ of methane in the northern hemisphere.

A selection of four records from the northern hemisphere of the NOAA data set between 1986 and 1988 is reproduced in Figure 4 and the locations of the sites are shown in Figure 5. The relatively regular seasonality in northern latitudes with the minimum in July and the maximum in December, exemplified by stations MBC and STM, is attributed to the seasonal change of the photochemical oxidation of $\mathrm{CH}_{4}$ by $\mathrm{OH}$ radicals. The more complex structure of variations south of $60^{\circ} \mathrm{N}$ (stations CBA and SHM) probably arises from a stronger influence from terrestrial sources [Steele et al., 1992]. At these stations, the winter maximum appears to be flattened by an additional mechanism which is interpreted as the inhibition of air-sea exchange of methane by the winter ice cover at these locations or adjacent areas and the freezing of the northern wetlands. Between March and May the retreating ice probably induces minor methane peaks with a maximum at the end of April, a feature that is frequently observed at these stations (cf. Figure 4c, 4d). With the onset of increased $\mathrm{OH}$ radical production in the late spring and early summer in the northern hemisphere, the excess methane is rapidly oxidized [Prinn, 1994]. Hence the exported maximum

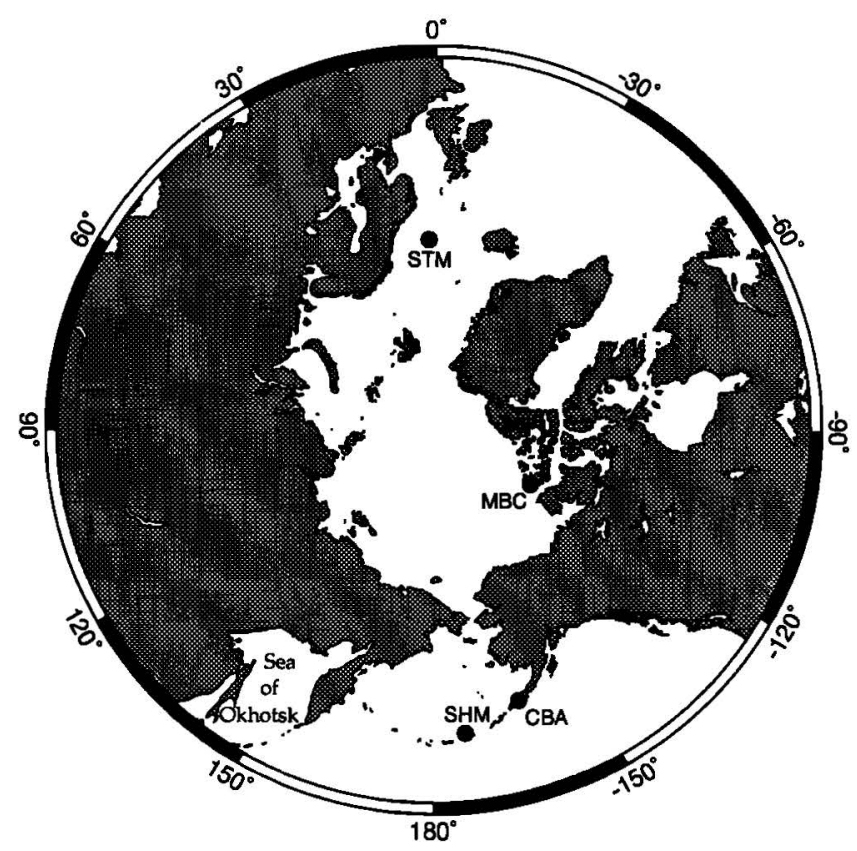

Figure 5. Locations of sampling sites in the North Pacific and the North Atlantic which are being referred to in Figure 4. The stations are selected from the NOAA-CMDL "cooperative flask sampling network" on which atmospheric methane is worldwide monitored [Lang et al., 1990]. SHM: Shemya Island (Alaska), CBA: Cold Bay (Alaska), MBC: Mould Bay (Canada), STM: "Station M" (Norwegian Sea). in methane resulting from either or both wetland or sea ice does not appear in the records, such that, rephrasing Prinn [1994], the chemistry still wins out in dominating the northern hemisphere $\mathrm{CH}_{4}$ cycle but the source cycle is still there as well.

The appearance of the small methane maxima in the records of Cold Bay and Shemya Island could be of rather restricted extent and duration. Generally, they may only be detectable at latitudes between $50^{\circ} \mathrm{N}$ and $60^{\circ} \mathrm{N}$, where the annual variation is less intensive and rapid mixing within the atmosphere delimits the time window for their detection. The magnitude of methane pulses responsible for these peaks can therefore hardly be evaluated from the response of the atmospheric record. Within an area covered by the Sea of Okhotsk $\left(1.4 \times 10^{6} \mathrm{~km}^{2}\right)$, an estimated release of $0.13 \mathrm{Tg}$ would induce a deviation from the average level of the order of $150 \mathrm{ppb}$ if atmospheric mixing is neglected. If the maximum of the above flux estimate and an effective lateral transport are considered, the observed short-term increase of 10-15 ppb can be expected in the vicinity of seasonally ice covered regions

On the other hand, the inhibition of the methane flux to the atmosphere, that is, the amount accumulated under the ice cover, may considerably exceed the amount released after the ice retreats. It is known that methane anomalies in oxic water columns are rapidly removed through microbial consumption and thus only a minor amount of the methane supply from sedimentary sources can escape the marine recycling [Ward et al., 1987; Reeburgh et al., 1992; Lammers et al., 1995]. Although the actual rates of oxidation in the water column are unknown for the ice covered Sea of Okhotsk, the recycled portion of methane probably exceeds the amount released more than ten-fold, based on our data from the Barents Sea [Lammers et al., 1995].

\section{Conclusions and Outlook}

From the present state of knowledge and the data obtained it is evident that the Sea of Okhotsk has a large potential as a net source of atmospheric methane. Seasonal ice cover reduces the sea-air exchange of methane during the winter season and induces a flux peak of the accumulated methane as it retreats. The estimated magnitude of these effects is large enough to contribute to the irregular distribution of atmospheric methane observed between $50^{\circ} \mathrm{N}$ and $60^{\circ} \mathrm{N}$ from October to April. However, on a larger scale, they do not appear to be a single significant feature of the annual variation of atmospheric methane in the northern hemisphere. More likely, the spring release of methane from parts of the Arctic Ocean somehow combines with and modulates other seasonal active sources in the northern hemisphere, that is, the Alaskan and Siberian tun- 
dra. The overall effect of methane from the Arctic Ocean on the atmospheric methane budget is probably small, on account of enhanced oxidation of the large amounts of methane which are trapped in the oxic water column. Methane consumption under seasonally icecovered parts of the ocean likely has a considerable effect on the marine methane cycle and thus appears to be a rewarding scientific topic for the future.

The expected relationship between ice-triggered methane accumulations and the marine methane cycle will be one subject of more detailed and long-term investigations intended for the Sea of Okhotsk and the Kuril Island Arc in future years. As part of a proposed joint Russian-German research program, a biogeochemical monitoring will attend to the variety of methane producing and consuming processes in this region.

Acknowledgments. We are indebted to numerous Russian colleagues for their support and hospitality during both expeditions to the Sea of Okhotsk, in particular the members of the Sakhalin Institute for Oil and Gas Research as well as captain and crew of RV Alexandr Nesmeyanov. Marta Torres and Christoph Gaedicke are acknowledged for their assistance. Helpful comments were contributed to this paper by Dr. Keith Kvenvolden and an anonymous reviewer.

\section{References}

Avdeiko, G.P., G.M. Gavrilenko, L.V. Chertkova, V.I. Bondarenko, V.A. Rashidov, V.I. Guseva, V.I. Maltseva, and A.P. Sazonov, Submarine hydrothermal activity off northwestern Paramushir (Kuri Islands), Volcanol. Seis., 6, 879-990, 1988.

Bange, H.W., U.H. Bartell, S. Rapsomanikis, and 0 . Andrae, Methane in the Baltic and the North Seas and a reassessment of the marine emissions of methane, Global Biogeochem. Cycles, 8, 465-480, 1994.

Blake, D.R., and F.S. Rowland, Continuing worldwide increase in tropospheric methane, Science, 239, 11291131, 1988.

Cicerone, R.J., and R. Oremland, Biogeochemical aspects of atmospheric methane, Global Biogeochem. Cycles, 2, 299-327, 1988.

Conrad, R., and W. Seiler, Methane and hydrogen in seawater (Atlantic Ocean), Deep Sea Res. Part A, 35, 1903-1917, 1988.

Cranston, R.E., G.D. Ginsburg, V.A. Soloviev, and T.D. Lorenson, Gas venting and hydrate deposits in the Okhotsk Sea, Bull. Geol. Soc. Den., 41, 80-85, 1994.

Fung, I., J. John, J. Lerner, E. Matthews, M. Prather, L.P. Steele, and P.J. Fraser, Three-dimensional model synthesis of the global methane cycle, J. Geophys. Res., 96, 13,033-13,065, 1991.
Geodekyan, A.A., V.Ya. Trotsyuk, and Z.I. Verkshovskaya, Hydrocarbon gases in bottom sediments of the Sea of Okhotsk (in Russian), Dokl. Akad. nauk SSSR, 226, 228-230, 1976.

Ginsburg, G.D., V.A. Soloviev, R.E. Cranston, T.D. Lorenson, and K.A. Kvenvolden, Gas hydrates from the continental slope, offshore Sakhalin Island, Okhotsk Sea, Geo Mar. Lett., 13, 41-48, 1993.

Kvenvolden, K.A., M.D. Lilley, T.D. Lorenson, P.W. Barnes, and E. McLaughlin, The Beaufort Sea continental shelf as a seasonal source of atmospheric methane, Geophys. Res. Lett., 20, 2459-2462, 1993.

Lammers, S., and E. Suess, An improved head-space analysis method for methane in seawater, Mar. Chem., 47, 115-125, 1994.

Lammers, S., E. Suess, and M. Hovland, A large methane plume east of Bear Island (Barents Sea): Implications for the marine methane cycle, Geol. Rundsch., 84, 59-66, 1995.

Lang, P.M., L.P. Steele, and R.C. Martin, Atmospheric Methane Data for the Period 1983-1986 from the NOAA/CMDL Global Cooperative Flask Sampling Network, National Oceanic and Atmospheric Administration, Boulder, Colo., 1990.

Obzhirov, A.I., Gasgeochemical manifestations of gasohydrates in the Sea of Okhotsk, Alaska Geol., 21, 1-7, 1992.

Obzhirov, A.I., B.A. Kazanskiy, and Yu.I. Melnischenko, Effects of sound dispersion in the near bottom water in marginal parts of the Okhotsk Sea (in Russian), Pac. Geol., 2, 119-121, 1989.

Owens, N.J.P., C.S. Law, R.F.C. Mantoura, P.H. Burkill, and C.A. Llewellyn, Methane flux to the atmosphere from the Arabian Sea, Nature, 354, 293296, 1991.

Prinn, R.G., The interactive atmosphere: Global atmospheric-biospheric chemistry, Ambio, 23, 50-61, 1994.

Rasmussen, R.A., and M.A.K. Khalil, Atmospheric methane $\left(\mathrm{CH}_{4}\right)$ : Trends and seasonal cycles, J. Geophys. Res., 86, 9826-9832, 1981.

Reeburgh, W.S., S.C. Whalen, and M.J. Alperin, The role of methylotrophy in the global methane budget, in Microbial Growth on C-1 Compounds, edited by J.C. Murrell and D. Welley, pp. 1-14, Intercept, Andover, Hampshire, 1992.

Schmitt, M., E. Faber, R. Botz, and P. Stoffers, Extraction of methane from seawater using ultrasonic vacuum degassing, Anal. Chem., 63, 529-531, 1991

Steele, L.P., E.J. Dlugokencky, P.M. Lang, P.P. Tans, R.C. Martin, and K.A. Masarie, Slowing down of the global accumulation of atmospheric methane during the 1980s, Nature, 358, 313-316, 1992.

Untersteiner, N., Structure and dynamics of the Arctic Ocean ice cover, in The Geology of North America, vol. L, The Arctic Ocean Region, edited by A. Grantz, 
L. Johnson, and J.F. Sweeney, pp. 37-52, The Geological Society of America, Boulder, Colo., 1990.

Wanninkhof, R., Relationship between wind speed and gas exchange over the ocean, J. Geophys. Res., 97, 7373-7382, 1992.

Ward, B.B., K.A. Kilpatrick, P.C. Novelli, and M.I. Scranton, Methane oxidation and methane fluxes in the ocean surface layer and deep anoxic waters, $\mathrm{Na}$ ture, 327, 226-229, 1987.

Whalen, S.C., and W.S. Reeburgh, Interannual variations in tundra methane emission: A 4-year time series at fixed sites, Global Biogeochem. Cycles, 6, 139-159, 1992.

Wiesenburg, D.A., and N.L. Guinasso, Equilibrium solubilities of methane, carbon monoxide and hydrogen in water and seawater, J. Chem. Eng. Data, 24, 356$360,1979$.
Zonenshayn, L.P., I.O. Murdmaa, B.V. Baranov, A.P. Koznetsov, V.S. Kurin, M.S. Barash, G.M. Valyashirv, and M. Demiral, An underwater gas source in the Sea of Okhotsk west of Paramushir Island, Oceanology, 27, 598, 1987.

V. V. Anikiev, Russian Academy of Science, Institute of Oceanology, Moskow, Russian Federation.

S. Lammers and E. Suess, GEOMAR, Forschungszentrum für marine Geowissenschaften, Wischhofstraße 1-3, 24148 Kiel, Germany.

(e-mail: slammers@geomar.de; esuess@geomar.de)

M. N. Mansurov, Sakhalin Institute for Oil and Gas Research, Okha, Sakhalin, Russian Federation.

(Received June 13, 1994; revised March 24, 1995; accepted April 6, 1995.) 